\title{
Parenting and Adjustment in Schizophrenia
}

Carol L. M. Caton, Ph.D. Francine Cournos, M.D. Boanerges Dominguez, M.S.

O bjective: Patients with schizophrenia who became parents and those who remained childless were compared on premorbid characteristics and current clinical and social adjustment. Methods: Subjects were $\mathbf{4 0 0}$ men and women with a DSM-III-R diagnosis of chronic schizophrenia based on the Structured Clinical Interview for D SM-III-R (SCID). Assessments measured concurrent substance abuse and antisocial behavior, positive and negative symptoms using the Positive and Negative Syndrome Scale, functional status using the G lobal Assessment of F unctioning scale, family support, and treatment compliance. A total of 158 patients were parents (47 men and 111 women), and 242 were childless (153 men and 89 women). Results: Compared with childless subjects, parents were more likely to have had better premorbid social adjustment, to have ever been married or involved in a conjugal relationship, and to have become ill at a later age. More than two-thirds of parents entered parenthood before the onset of schizophrenia. More women than men were parents, and parents were more likely to be members of ethnic minority groups. No differences were found in current clinical and social adjustment of parents and childless subjects. Conclusions: Parenthood was associated with better premorbid social adjustment, but it conferred no advantage in the long-term course of schizophrenia. Patients who experience a later onset of schizophrenia or have better premorbid social skills may be more likely to undertake marriage and parenthood, but they will then also be more likely to need special support for the parenting role once the illness begins and takes its typical course. (Psychiatric Services 50:239-243, 1999)

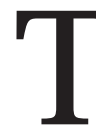

he era of community-based treatment for serious mental illness has witnessed greater numbers of men and women with schizophrenia experiencing parenthood $(1,2)$. Considerable evidence exists that the fertility rate of people with schizophrenia, which was far below that of the general population before the late 1950s (3), increased markedly following deinstitutionalization of mental health services
$(1,2,4)$. It has been estimated that the fertility rate of women with schizophrenia now approaches that of the general population (2), with whom former patients share the universal aspirations to establish intimate ties and have children.

An increasing number of descriptive studies based on small, selected samples have explored sexuality, pregnancy experiences, and childrearing among women with schizophrenia
The authors are affiliated with the department of psychiatry at the College of Physicians and Surgeons of Columbia University, 1052 Riverside Drive, Unit 56, N ew York, New York 10032 (e-mail, clc3@columbia.edu). This paper was presented at the annual meeting of the American Psychiatric Association held M ay 17-22, 1997, in San Diego.
(5-10). Such studies have revealed that pregnancies are often unplanned (5-7) and that only a minority of patient-parents are able to provide consistent nurturing of their children due to the chronic and relapsing nature of schizophrenia and its accompanying social disability (8-10). H owever, very little research has examined the association between parenting and premorbid characteristics of patients or the course and outcome of their illness. This paper is one attempt to address that gap.

In this study, we explored the clinical, demographic, and background characteristics and social functioning of patients with schizophrenia who became parents and those who remained childless. We examined whether parents differed from childless subjects in premorbid characteristics or clinical and social adjustment. We discuss the findings in relation to the expanding literature on parenting and schizophrenia.

Methods

Study subjects were 400 men and women with chronic schizophrenia originally selected on the basis of their housing history in connection with a cross-sectional study of risk factors for homelessness. All subjects had experienced at least one psychiatric hospitalization and were between the ages of 18 and 64 years. $\mathrm{H}$ alf the patients in the sample were currently residing at a shelter for the homeless, and the other half were psychiatric outpatients or dischargeready inpatients on public psychiatric units for patients with severe mental illness. To be eligible for inclusion in the study, subjects were 


\section{Table 1}

Characteristics of 400 subjects with schizophrenia, by parental status

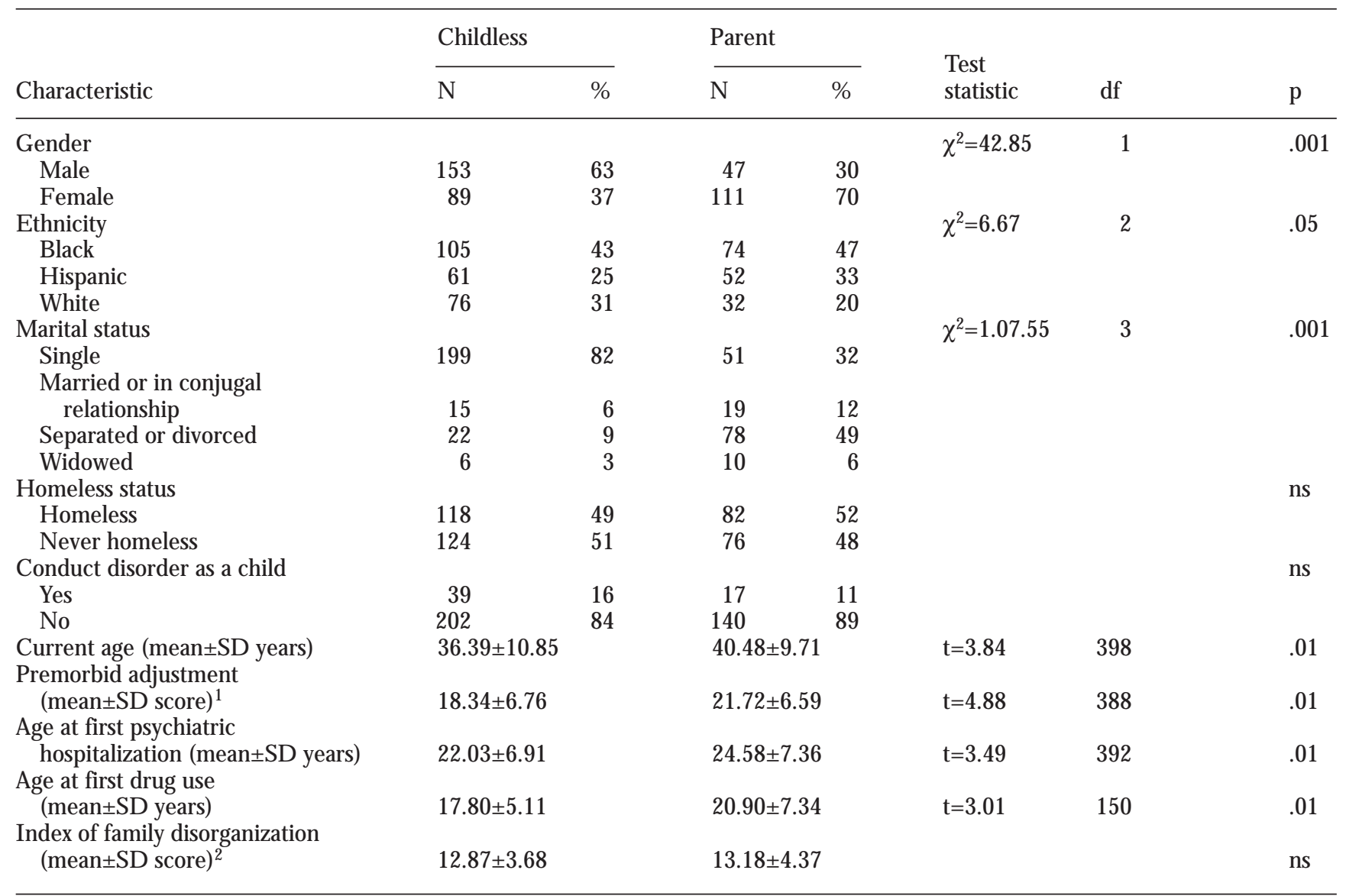

1 Possible scores range from 7 to 35 , with higher scores indicating better adjustment.

2 Possible scores range from 8 to 32, with higher scores indicating greater disorganization.

required to meet DSM-III-R criteria for schizophrenia or schizoaffective disorder, which was determined through the Structured Clinical Interview for D SM -III-R (SCID) (11).

Potential study subjects were referred by clinical staff based on the subject's chart diagnosis, treatment history, and ability to give voluntary informed consent. A total of 497 subjects, recruited consecutively between 1988 and 1992 from shelters for the homeless and mental health inpatient and outpatient programs in an urban area, were asked to participate in the study. Thirty subjects ( 6 percent) refused, and 34 (7 percent) dropped out before completing the interview. Thirty-three subjects (7 percent) with completed interviews were eliminated because of inconsistent or poor-quality data that could not be improved with a re-interview. The remaining 80 percent of subjects constituted the sample of 400 .
Subjects were interviewed by mental health clinicians experienced in working with severely mentally ill patients. They were specially trained to administer the research instruments used in this investigation. Clinical and anamnestic data were verified with information contained in the clinical case record. When both the patient and a relative agreed, an hour-long interview with a family member was also carried out. All study subjects provided written informed consent before being interviewed.

Research instruments used to assess key study variables, which are described elsewhere (12), are summarized briefly here. Premorbid social functioning was rated with the LOS Angeles Social Attainment Scale, a seven-item instrument that is focused on peer relationships and social participation in late adolescence (13). The alpha reliability coefficient for this scale is .80 .
The positive dimensions of schizophrenia (active psychotic symptoms such as delusions, hallucinatory behavior, and conceptual disorganization) and the negative dimensions (deficit symptoms such as blunted affect, emotional withdrawal, and difficulty with abstract thinking) were assessed with the Positive and $\mathrm{N}$ egative Syndrome Scale, a 30-item rating scale evaluating symptoms present during the seven days before the interview (14). The al pha reliability coefficient was. 79 for the positive scale, .84 for the negative scale, and .83 for the general psychopathology scale.

Current and lifetime alcohol and drug abuse or dependence were evaluated with the SCID, which yields information on the extent to which heavy use of alcohol or seven classes of drugs meets criteria for a diagnosis based on standards commonly applied in psychiatry (11).

Antisocial personality disorder was 
evaluated with the SCID-II, which deals with personality disorders (11). This instrument probes for the presence of conduct problems occurring before the age of 15 , such as running away from home, being a truant from school, initiating physical fights, or belonging to a gang, as well as patterns of irresponsible, destructive, or illegal activity carried over into adulthood. F or a subject to meet criteria for a diagnosis of antisocial personality disorder, a conduct disorder must have been present in early adolescence. The SCID also rates axis V, social functioning, on the Global Assessment of $\mathrm{F}$ unctioning Scale, with ratings from 0 , poor, to 100 , best.

$F$ amily disorganization in childhood was evaluated with 4-point rating scales contained in the Community Care Schedule (15). These ratings are based on carefully defined anchor points for the assessment of nurturing constancy, residential stability, adequacy of income, dependence on public assistance, family violence, parental criminality, parental mental illness, and parental substance abusethe components of an index of family disorganization. Information for this instrument was elicited from both the subject and a family member whenever possible to obtain the most complete picture of family life during the subject's childhood. The alpha reliability coefficient for the seven-item index of family disorganization is .69.

Current family support was rated on a scale of adequacy, based on the degree of support and assistance available from family members in the areas of money, shelter, food, clothing, advice, and companionship (15). Information for this rating was obtained from the subject and corroborated by a relative when possible.

Prior service use was explored with items contained in the Community Care Schedule that were designed to elicit detailed information on medication compliance patterns, long-term follow-up care, and rehospitalization episodes. M edication compliance was rated on a 4-point scale based on the subject's self-report. L ong-term follow-up care was defined in terms of the number of months in outpatient treatment with the same therapist. The number of days hospitalized in

\section{Table 2}

Current clinical and social functioning of 400 subjects with schizophrenia, by parental status ${ }^{1}$

\begin{tabular}{|c|c|c|c|c|}
\hline \multirow[b]{2}{*}{ Characteristic } & \multicolumn{2}{|c|}{ Childless } & \multicolumn{2}{|c|}{ Parent } \\
\hline & $\mathrm{N}$ & $\%$ & $\mathrm{~N}$ & $\%$ \\
\hline \multicolumn{5}{|l|}{ Currently working } \\
\hline Yes & 100 & 41 & 53 & 34 \\
\hline No & 142 & 59 & 105 & 67 \\
\hline \multicolumn{5}{|l|}{ Alcohol abuse } \\
\hline Yes & 89 & 37 & 49 & 31 \\
\hline No & 151 & 63 & 109 & 69 \\
\hline \multicolumn{5}{|l|}{ Cannabis abuse } \\
\hline Yes & 98 & 41 & 40 & 25 \\
\hline No & 143 & 59 & 118 & 75 \\
\hline \multicolumn{5}{|l|}{ Cocaine abuse } \\
\hline Yes & 77 & 32 & 43 & 27 \\
\hline No & 164 & 68 & 114 & 73 \\
\hline \multicolumn{5}{|l|}{ Antisocial personality disorder } \\
\hline Yes & 43 & 18 & 17 & 11 \\
\hline No & 199 & 82 & 141 & 89 \\
\hline \multicolumn{5}{|l|}{ F amily support } \\
\hline Adequate & 119 & 50 & 68 & 44 \\
\hline Fair & 29 & 12 & 25 & 16 \\
\hline Poor & 29 & 12 & 19 & 12 \\
\hline Grossly inadequate & 62 & 26 & 43 & 27 \\
\hline \multicolumn{5}{|l|}{ 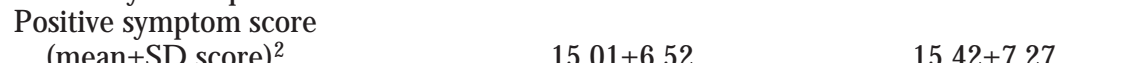 } \\
\hline \multirow{5}{*}{$\begin{array}{l}\mathrm{N} \text { egative symptom score } \\
\text { (mean } \pm S D \text { score) }^{2} \\
\text { G lobal Assessment of } F \text { unctioning } \\
\text { (mean } \pm D \text { score) }^{3} \\
\text { M edication compliance } \\
\text { (mean } \pm S D \text { score) } \\
\text { Total days hospitalized in the past }\end{array}$} & \multicolumn{2}{|c|}{$15.01 \pm 6.52$} & \multicolumn{2}{|c|}{$15.42 \pm 7.27$} \\
\hline & \multicolumn{2}{|c|}{$16.63 \pm 6.49$} & \multicolumn{2}{|c|}{$17.55 \pm 6.88$} \\
\hline & \multicolumn{2}{|c|}{$40.52 \pm 11.4$} & \multicolumn{2}{|c|}{$40.43 \pm 12.2$} \\
\hline & \multicolumn{2}{|c|}{$1.64 \pm .96$} & \multicolumn{2}{|c|}{$1.71 \pm .99$} \\
\hline & \multirow{2}{*}{\multicolumn{2}{|c|}{$63.65 \pm 75.71$}} & \multirow{2}{*}{\multicolumn{2}{|c|}{$75.94 \pm 104.83$}} \\
\hline $\begin{array}{l}\text { Total days hospitalized in the past } \\
\text { year (mean } \pm S D \text { days) }\end{array}$ & & & & \\
\hline
\end{tabular}

${ }_{1}$ No significant differences were found between groups.

2 Possible scores range from 7 to 49 , with higher scores indicating greater impairment.

3 Possible scores range from 0 to 100, with higher scores indicating better functioning.

${ }^{4}$ Possible scores range from 1 to 4 , with higher scores indicating poorer compliance.

the past 12 months was recorded based on the subject's self-report.

We described the differences between parent and childless groups in demographic, background, and clinical characteristics and social functioning. These variables were summarized as percentages for categorical variables and means for quantitative variables. Pearson chi square and $t$ test statistics were used to study statistical differences between the parent and childless groups.

\section{Results}

Background characteristics

Of the 400 subjects, 158 were parents. The majority of patients who were parents had their first child before their first hospitalization for schizophrenia-102 patients, or 65 percent. Parents had a total of 319 offspring, an average of two per patient. A total of 232 offspring ( 73 percent) were born before the parent's illness, while 87 (27 percent) were born after the parent's first hospitalization.

Background characteristics of study subjects based on parental status are shown in Table 1. Statistically significant differences were found between parents and childless patients in gender, ethnicity, and marital status. Women were more than twice as likely as men to report having children; 70 percent of the parents were women. $M$ en dominated the childless category; 63 percent of childless subjects were men.

Compared with white patients, a greater number of blacks and $\mathrm{H}$ ispan- 
ics had become parents, while a greater number of whites had remained childless. Not surprisingly, the majority of parents (about twothirds) had been married or involved in a conjugal relationship, while the vast majority of childless patients (82 percent) had remained single. As Table 1 shows, parents were an average of four years older than childless subjects, a significant difference. No significant difference in homeless status was found between parents and childless subjects.

When the two groups were compared on characteristics of illness and social history, interesting differences emerged. As shown in Table 1, parents had significantly better premorbid social adjustment scores than childless subjects. Childless subjects experienced their first psychiatric hospitalization at a significantly earlier age than subjects who were parents. Childless subjects also initiated drug use at a significantly earlier age than parents. H owever, childless subjects and parents did not differ significantly in childhood experiences and parental pathology as assessed with the index of family disorganization; no difference between groups was found in a diagnosis of conduct disorder before the age of 15 years.

When scores for premorbid adjustment were adjusted for gender, ethnicity, marital status, age of first hospitalization, and age of first drug use, parents were 2.5 times more likely than childless subjects to have a better score.

Clinical and social functioning Current clinical and social functioning of parents and childless subjects were compared (Table 2). No significant differences were found in current work status, diagnoses of substance abuse or antisocial personality disorder, positive or negative symptoms, Global Assessment of Functioning score, adequacy of family support, medication compliance, or days hospitalized in the past year.

\section{Discussion and conclusions}

We examined parenting and adjustment using data from 400 men and women with a DSM-III-R diagnosis of schizophrenia or schizoaffective disorder who were originally selected for a study of risk factors for homelessness. $\mathrm{H}$ alf the subjects were homeless when they were interviewed, and although the other half had never been literally homeless, they shared many of the social characteristics (minority ethnic status) and economic characteristics (living on the edge of poverty) of homeless subjects. We found important differences in the characteristics of subjects with schizophrenia who became parents and those who remained childless. Compared with childless subjects, parents were more likely to have had better premorbid social ad-

\section{The majority \\ of parents had their}

first child before the onset

$$
\text { of their illness, and only a }
$$

\section{quarter of the children were}

\section{born after the parent's}

\section{first psychiatric}

hospitalization.

justment, to have ever been married or involved in a conjugal relationship, and to have experienced the onset of illness at a later age.

The majority of parents had their first child before the onset of their illness, and only a quarter of the children (27 percent) were born after the parent's first psychiatric hospitalization. Therefore, deinstitutionalization did not appear to be an important factor in why these patients became parents. M ore women than men became parents. The fact that age of onset of schizophrenia is often later in women than men may at least partly account for this finding $(16,17)$. Parents were more likely than childless subjects to be members of ethnic minority groups.

It is possible that an important component of the gender difference in parenthood is the biological inevitability that women bear the reproductive consequences of sexual activity. M en may not always have knowledge that a pregnancy has occurred as a result of sexual activity, particularly if it occurs outside of a meaningful relationship. Recent research on the sexual behaviors of people with severe mental illness, carried out in connection with research on HIVAIDS risk assessment, has revealed that the rates of sexual activity for men and women are comparable (18). Unprotected sexual activity is widespread among persons with severe mental illness. The fact that women are more often faced with the outcome of unprotected sexual activity underscores their need for access to family planning and reproductive services in settings that treat women with schizophrenia (19).

No differences were found in the current clinical and social adjustment of parents and childless subjects. $\mathrm{H}$ owever, parents' adjustment was no better than that of childless subjects, even though parents had better premorbid adjustment and were more likely to have established at least a temporary relationship with a significant other. Thus parenthood did not have a favorable impact on the clinical course of schizophrenia, and it may be that the stressors of the parenting role offset whatever advantages were conferred on parents by better premorbid functioning.

H owever, our findings are preliminary and require replication with socially and economically diverse samples of people with schizophrenia. Because our study was cross-sectional, we might have missed fluctuations or changes in clinical and social functioning over time that might be related to life events occurring in relation to parenting, such as the impact of pregnancy (20) and the postpartum period or loss of custody of children. At the very least, adjustment of medications, as well as awareness of their safety profiles in pregnant and nursing women, can become an important clinical issue. 0 ur measures of adjustment did not address the fact that parenting is a life role that can be enriching and growth enhancing. 
An important caveat is that even if being a parent or remaining childless does not alter the course of severe mental illness, parenthood can impose increased stresses and challenges for parents with schizophrenia and for their children, requiring specialized mental health treatment and support services (20-25). A previously reported study of the offspring of these subjects found that most patient-parents lived with their offspring at some time but relied heavily on relatives and other adults to provide their offspring with consistent nurturing (26). As many as a third had children placed in foster care.

In conclusion, patients who experience a later onset of schizophrenia or have better premorbid social skills are more likely to undertake marriage and parenthood. Whether offspring are born before or after the parent's onset of illness, patient-parents are likely to need special support for the parenting role once the illness begins and takes its typical course (27).

\section{References}

1. E rlenmeyer-Kimling L, Nichol S, Rainer JD, et al: Changes in fertility rates in schizophrenic patients in N ew York State. American Journal of Psychiatry 125:916-927, 1969

2. Burr WA, F alek A, Strauss LT, et al: F ertility in psychiatric outpatients. Hospital and Community Psychiatry 30:527-531, 1979

3. E rlenmeyer-Kimling L, Rainer JD, Kallman FJ: Current reproductive trends in schizophrenia, in Psychopathology of Schizophrenia. E dited by H och PH, Zubin J. N ew York, Grune \& Stratton, 1966

4. Shearer ML, Cain AC, F inch SM, et al: Unexpected effects of an "open door" policy on birth rates of women in state hospitals. American Journal of Orthopsychiatry 138: 413-417, 1968

5. Coverdale JH, Aruffo JF : F amily planning needs of female chronic psychiatric outpatients. American Journal of Psychiatry 146: 1489-1491, 1969

6. Rudolph B, Larson GL, Sweeny $S$, et al: Hospitalized pregnant psychotic women: characteristics and treatment issues. $\mathrm{H}$ ospital and Community Psychiatry 41:159-163, 1990

7. M iller LJ, F innerty $M$ : Sexuality, pregnan$c y$, and childbearing among women with schizophrenia-spectrum disorders. Psychiatric Services 47:502-506, 1996

8. Test MA, Burke SS, Walisch LS: Gender differences of young adults with schizophrenic disorders in community care. Schizophrenia Bulletin 16:331-334, 1990
9. White $\mathrm{CL}, \mathrm{N}$ icholson J, F isher WH, et al: $M$ others with severe mental illness caring for children. Journal of N ervous and $\mathrm{M}$ ental D isease 183:398-403, 1995

10. Grunbaum L, Gammeltoft M : Young children of schizophrenic mothers: difficulties of intervention. American Journal of Orthopsychiatry 63:16-27, 1993

11. Spitzer RL, Williams JBW, Gibbon M, et al: Structured Clinical Interview for D SM -IIIR. Washington, DC, American Psychiatric Press, 1990

12. Caton CLM, Shrout PE, Eagle PF, et al: Risk factors for homelessness among schizophrenic men: a case-control study. American Journal of Public Health 84:265-270, 1994

13. Goldstein M J: F urther data concerning the relation between premorbid adjustment and paranoid symptomatology. Schizophrenia Bulletin 4:236, 1978

14. Kay SR, F iszbein A, O pler LA: The Positive and N egative Syndrome Scale (PAN SS) for schizophrenia. Schizophrenia Bulletin 13:261-275, 1987

15. Caton CLM : The Community Care Schedule. N ew York, N ew York State Psychiatric Institute, Jan 1989

16. Shtasel DL, Gur RE, Gallacher F, et al: Gender differences in the clinical expression of schizophrenia. Schizophrenia Research 7:225-231, 1992

17. $\mathrm{H}$ ambrecht $M, M$ aurer $K, H$ äfner $H$ : Gender differences in schizophrenia in three cultures. Social Psychiatry and Psychiatric E pidemiology 27:117-121, 1992

18. M cKinnon K: Risk behavior assessment, in AIDS and People With Severe M ental IIIness. E dited by Cournos F, B akalar N. N ew H aven, Conn, Yale U niversity Press, 1996
19. Cournos F, Bakalar N (eds): AID S and People With Severe M ental I IIness, ibid

20. Apfel RJ, $\mathrm{H}$ andel $\mathrm{MH}$ : $\mathrm{M}$ adness and Loss of M otherhood: Sexuality, Reproduction, and Long-Term M ental IIIness. Washington, DC, American Psychiatric Press, 1993

21. M owbray CT, Oyserman D, Zemencuk JK, et al: $M$ otherhood for women with serious mental illness: pregnancy, childbirth, and the postpartum period. American Journal of Orthopsychiatry 65:21-38, 1995

22. Wang AR, Goldschmidt VV: Interviews of psychiatric inpatients about their family situation and young children. Acta Psychiatrica Scandinavica 90:459-465, 1994

23. Sands RG: The parenting experience of low-income single women with serious mental disorders. J ournal of Contemporary H uman Services 76:86-96, 1995

24. Cohler B, Musick J (eds): Intervention With Psychiatrically D isabled Parents and Their Young Children. N ew Directions for M ental H ealth Services, no 24, 1984

25. Blanch AK, Nicholson J, Purcell J: Parents with severe mental illness and their children: the need for human service integration. J ournal of M ental $\mathrm{H}$ ealth Administration 21:388-396, 1994

26. Caton CLM, Cournos F, F elix A, et al: The Children of $D$ einstitutionalization: N eeds Assessment of the Children of the Severely M entally III. Final Report to the N ew York Community Trust. New York, New York Community Trust, Jan 30, 1996

27. K rener $P$, Simmons M K, H ansen RL, et al: $E$ ffect of pregnancy on psychosis: life circumstances and psychiatric symptoms. International Journal of Psychiatry in M edicine 19:65-84, 1989

\section{Review ers Needed}

Psychiatric Services seeks expert reviewers in the following areas:

Collaborative activities with the police

- Experiences of patients and former patients

- Telemedicine and telecommunications

- Outcome and clinical measurement scales

- D epot medications

Reviewers should be familiar with the literature in their areas of expertise, should have published in peerreviewed journals, and should be familiar with the content and focus of Psychiatric Services. Prospective reviewers should send a curriculum vitae, specifying areas of interest, to J ohn A. Talbott, M .D ., E ditor, Psychiatric Services, APA, $1400 \mathrm{~K}$ Street, N.W., Washington, D.C. 20005 (e-mail, psjournal@psych.org). 